\title{
Fale com eles: mídia jovem e visibilidade juvenil
}

Rosamaria Luiza (Rose) de Melo Rocha

Doutora em Ciências da Comunicação pela Escola de Comunicação e Artes da Universidade de São Paulo (ECA-USP), com pós-doutorado em Ciências Sociais pela Pontifícia Universidade Católica de São Paulo (PUC/SP). Professora e pesquisadora do mestrado em Comunicação e Práticas do Consumo da Escola Superior de Propaganda e Marketing (ESPM/SP). Professora do Departamento de Arte da Pontifícia Universidade Católica de São Paulo (PUC/SP). E-mail: rlmrocha@uol.com.br

Interessa-nos, nesta crítica, apresentar de modo sintético alguns dos operadores conceituais que vem sendo utilizados na análise da chamada mídia jovem. Nessa definição incluem-se veículos ou encartes periódicos da mídia massiva voltados ao segmento juvenil, seja para tematizá-lo, seja para com ele dialogar na consideração de sua relevância nas dinâmicas de consumo.

A interpretação aqui proposta foca a relação entre a eficácia comunicativa dos produtos midiáticos e a inserção do jovem em macroprocessos de visibilidade. Assim, considera-se que elementos formais, aportes de conteúdo, projetos gráficos e linhas editoriais, articulando modos de ver, direcionamentos do olhar, imagens visuais e textuais, não só participam de modo relevante dos processos de visualidade e da juvenilização da cultura, mas, antes, oferecem poderosas senhas de acesso à aquisição de visibilidade sociocultural adquirida através da entrada em um muito peculiar universo juvenil. Este, cada vez mais permeado pelos hábitos de consumo, é peça-chave na consolidação contemporânea do campo midiático.

Para a finalidade específica desta crítica, adotaremos uma referência midiática particular. A revista Capricho (Editora Abril), há mais de cinqüenta anos no mercado editorial brasileiro, e, desde a década de 1960, direcionada ao público juvenil feminino, é o veículo escolhido para ilustrar algumas das hipóteses teóricas com as quais temos trabalhado. A análise que estamos desenvolvendo no projeto de pesquisa "Imagens Limiares e Visualidades Juvenis. Uma Imagética do Consumo", sediado na ESPM/SP, prevê a realização de estudos comparativos entre diferentes veículos, que, certamente, trarão novos matizes às reflexões aqui apresentadas.

\section{A RELAÇÃO PÚBLICO-REVISTA}

Dentre as estratégias adotadas para o estreitamento de vínculo com o público, a revista Capricho é representante emblemática de uma parcela da mídia jovem que propõe aos leitores a criação de todo um cenário ou cena 
interpretativa na qual se articulam - de modo seqüencial, relacional e pouco hierárquico - diferentes fragmentos de visualidade e variadas proposições de visibilidade. Tal recurso, mais restrito se considerarmos os encartes em jornais de grande circulação, adquire importância superlativa nessas revistas semanais.

Encontramos em revistas como Capricho uma proposta de leitura e a suposição de um leitor apto e habituado a reconhecer e adotar ferramentas de compreensão hipertextuais. Pode-se assim, sem prejuízo da credibilidade do veículo, trabalhar tanto de modo sutil quanto explícito rupturas de fronteiras entre as narrativas de teor jornalístico e os espaços destinados à veiculação de material publicitário. Ambos, compondo um incessante diálogo, fazem ressoar modelos ideais de comportamento, sugestões acerca de estilo de vida, parâmetros de apresentação corporal e, obviamente, um verdadeiro álbum imagético que se oferece como referencial para construções identitárias.

Se seguirmos o raciocínio proposto por Arthur Kroker e David Cook ${ }^{1}$, seria possível identificar aí a operação de uma estratégia midiática de estetização de princípios mercadológicos. Segundo esses autores, a mídia, como um aparato social abrangente, mais bem coloniza a psicologia individual sendo um determinador de estados de espírito [mood setter]. Coaduna-se, portanto, com a propagação de imagens um gerenciamento sensorial e comportamental decisivo, como se roupas, adereços, CDs e colunas testemunhais compusessem uma curiosa bricolagem, um guia sobre como sentir e como se sentir.

Ou seja, se voltarmos à Capricho, não se trata apenas de experimentar os novos cosméticos para a balada. O convite é utilizar, por exemplo, "perfumes, sombras e esmaltes para quebrar tudo na balada"2. Ou, ainda, não apenas pintar os cabelos, mas "perder o medo da cor"3. Os shortinhos apresentados em seções sobre moda aludem a praticidade e conforto; as estampas de verão remetem ao imaginário tropical; as roupas de grife oferecem citações sofisticadas aos "balneários chiques, como Saint-Tropez e Mônaco", ou a associações inusitadas,

OKER, Arthur; COOK, David. The postmodern scene: excremental culture and hyper-aesthestics (A cena pós-moderna: cultura excremental e hiperestética). Montreal: New World Perspectives, 1991.

2. CAPRICHO. São Paulo: Ed. Abril, n. 975, 18 set. 2005. p. 49.

3. Ibid., p. 53.

4. Ibid., p. 72.

5. Ibid., p. 73.

6. KROKER, Arthur; COOK, David, op. cit., p. 268.

7. DEBORD, Guy. A sociedade do espetáculo. Rio de Janeiro: Contraponto, 1997. como no caso de vestidos inspirados "na cultura egípcia e no rock"5.

As imagens assim compartilhadas são formas seriais de modos de ser, espectros a serem alegremente consumidos. Embora analisem especificamente a televisão, a interpretação de Kroker e Cook é pertinente para abranger o significado da cena midiática articulada por Capricho. Na proposição dos pesquisadores, a tevê, e, segundo sugerimos, a mídia, pode ser definida como expressão paroxística da forma-mercadoria, "vivendo finalmente (como Marx profetizou) como uma pura imagem-sistema, como uma imagem televisiva espectral" ". A reificação, nesses termos, é solapada pela linguagem da significação. Podemos notar as sutis inversões feitas por nossos autores na passagem em que comentam a clássica abordagem de Guy Debord ${ }^{7}$ sobre a espetacularização da sociedade. Vejamos o que nos dizem:

Em A Sociedade do Espetáculo, Guy Debord ressalta que o espetáculo é o capital em um tal grau de acumulação que se torna uma imagem. Isto é a tevê: ela é o break-point no qual o capital em sua forma final e mais avançada como uma ima- 
gem espectral começa a desaparecer em si mesmo e se torna aquilo que sempre foi: um signo-sistema vazio e niilista de pura mediação e de pura troca, o qual, não tendo mais energia própria, [suga] qualquer elemento vivo na cultura, na sociedade ou na economia ${ }^{8}$.

Corroborando e ampliando essa abordagem, encontramos em Fredric Jameson $^{9}$ a seguinte leitura do mesmo Debord, que aqui nos interessa destacar:

[...] temos que voltar à teoria da imagem, recolocando a notável derivação teórica de Guy Debord (a imagem como a forma final de reificação da mercadoria). Nesse ponto, o processo se reverte, e não são os produtos comerciais do mercado que se tornam imagens na propaganda, mas sim os próprios processos de diversão e de narrativa da televisão comercial que são, por sua vez, reificados e transformados em mercadorias ${ }^{10}$.

Mais do que excesso ou pura e simples obscenidade das imagens, depreendemos dos discursos de Jameson e de Kroker \& Cook uma pista analítica à qual iremos nos remeter. Trata-se, em resumo, da inserção original das imagens na malha cultural e nas interações sociais contemporâneas, através da qual o consumo de imagens/sensações e de imagens/estilos de vida, lógica familiar a estratégias publicitárias, estende-se ao campo propriamente jornalístico. Esse mercado de imagens é, também, uma imagem-mercado e um mercado de sensações.

O consumo material e simbólico conduz e roteiriza entrevistas nas quais se abordam celebridades midiáticas. É o caso da reportagem de capa que traz como personagem e fio-condutor Marjorie Estiano, assim apresentada: "125 mil CDs, um DVD a caminho" "1. Reiterando uma dinâmica auto-referente e circular, a atriz de 23 anos, que se lançou como cantora a partir de uma inserção, ficcional, na minissérie adolescente Malhação (Rede Globo) e dali saltou para as paradas, reais, de sucesso, serve também de link para outras reportagens da edição de Capricho: o Guia Capricho de música na internet e a matéria sobre a onda das camisetas surradas.

É interessante notar, nesse aspecto, a utilização do corpo da atriz como base de articulação e inscrição de marcas textuais. Suporte no qual se sobrepõem as diferentes chamadas para matérias da edição, o corpo de Estiano - um corpo jovem e belo - serve igualmente de mídia para a promoção de bens de consumo notadamente culturais: os fones de ouvido, a camiseta de grife - devidamente surrada - e todo um estilo de composição visual - pele clara, maquiagem suave, cabelos curtos, tingidos e desalinhados - que reforçam, como recurso metanarrativo, a própria imagem da leitora ideal de Capricho, aquela que quer ser diferente para ser ela mesma.

A autocelebração midiática, teorizada por autores como Michel Kokoreff ${ }^{12}$, ganha aqui uma imponderável articulação com hábitos e experiências vivenciados no dia-a-dia. Segundo Kokoreff, há uma tendência de que a televisão, o rádio, a imprensa e a publicidade dêem importância desmesurada a eles mes-

8. KROKER, Arthur; COOK, David, op. cit., p. 276.

9. JAMESON, Fredric. Pós-modernismo: a lógica-cultural do capitalismo tardio. São Paulo: Ática, 1996. p. 282-284.

10. Ibid., p. 283.

11. CAPRICHO, op. cit.

12. KOKOREFF, Michel. L'auto célébration de la télévision et ses paradoxes (A autocelebração da televisão e seus paradoxos). Quaderni, Paris, CREDAP, Université Paris Dauphine, n. 4, p. 37-43, primavera 1988 . 
mos. Nessa leitura, tal tendência traduz uma transformação global dos modos sociais de representação e de troca, segundo a qual os meios de comunicação tornam-se seu próprio fim. Mobilizando os signos de sua excelência, exibindo a matriz técnica, a mídia se autonomiza, joga com a fascinação das imagens, em detrimento da significação.

Não há inocência na incitação ao diálogo, à interação que ela promove. Nesse processo, que o autor compara a um reaquecimento do social, já não se trata mais de mobilizar a opinião pública, mas, sim, de fazer do social um grande show: "pelo poder mágico da tela, os problemas da sociedade se metamorfoseiam em acontecimentos midiáticos. Desinvestidos de sua carga negativa, submetidos a um tratamento emocional de superfície" ${ }^{13}$, esses problemas são absorvidos, persuadindo-nos, paradoxalmente, da necessidade e da grandeza do duplo midiático.

Às leitoras de Capricho é oferecida a possibilidade de assumirem em relação à cena midiática uma função especular. Mirar-se nas imagens das celebridades televisivas, por exemplo, serve de mote tanto para iniciativas da mais pura adesão - quando fotos de atrizes oferecem acessíveis flashes de modos de se vestir e de se posicionar - quanto naquelas em que a imagem da estrela confirma a impossibilidade da identificação, caso, por exemplo, da nota intitulada "Inveeeeeja!" sobre a "barriguinha que a Carolina Dieckmann, 26 anos e mãe de um filho, anda desfilando por aí" ${ }^{14}$.

Por sua vez, as peças publicitárias ancoram-se em apelos morais e moralizantes, indicando questionáveis regras de conduta às jovens consumidoras. São ali oferecidos modelos comportamentais nos quais as dinâmicas e conflitos cotidianamente experimentados pelas leitoras recebem destinações e soluções imediatas: Quer uma dica para conquistar os garotos?, A gente acabou de dar doze (anunciando artigos da megastore Renner) ${ }^{15}$, ou ainda Esse é para beijar! Tem beijo no rosto, na boca, selinho, técnico, quem joga escolhe e drácula - começa na boca e termina no pescoço ${ }^{16}$ (anúncio do dadinho do beijo que oferece, como brinde, gel refrescante bucal Splish!, "para usar antes de beijar") ${ }^{17}$.

$\mathrm{O}$ anúncio do absorvente Intimus Gel, "aquele que entende você", corrobora a manutenção do feminino em lugares da mais ativa subserviência:

Por que as mulheres têm de ter tanta paciência? Porque só elas levam cantadas abusadas na rua. Porque elas têm que ficar esperando ele ligar no dia seguinte. Porque elas têm muito mais coisas para agüentar! Intimus é como as mulheres: agüenta muito mais. Porque ele tem Dupla Segurança: para absorver mais rápido e por muito mais tempo ${ }^{18}$.

Gerenciando e colocando em pauta os assuntos relevantes e as soluções eficazes capazes de dar conta da inserção otimizada no mundo da visibilidade e do reconhecimento, a revista alimenta um poderoso agenciamento de subjetividades juvenis. Nesses lugares especiais, adquirir aceitação e ser bem- 
sucedido passa por saber administrar valores e expectativas, conferindo ao trato das frustrações um inegável valor de marca. A garota que se dá bem é aquela capaz de combinar, com a mesma astúcia e delicadeza, peças de roupa, modos de beijar, enfrentamentos geracionais, cuidados com o corpo e artimanhas de sedução.

\section{OS DISCURSOS ORDENADORES}

São bastante interessantes os contratos de visibilidade que esse veículo estabelece com suas leitoras. Capricho é este lugar seu que forja aconchego ao universalizar dilemas pessoais e ao personalizar embates universais vividos pelas jovens leitoras.

A revista já diz a que veio logo na capa. Afinal, ela é a revista que propõe às jovens o mote Seja diferente. Seja você. $O$ discurso da diferença que perpassa suas matérias e suas inserções publicitárias recebe, em alguns aspectos, curiosos contrapontos. Diferentes pero no mucho, uma vez que se nota em Capricho o assumido partidarismo da juvenilização como meta. Não é de estranhar que no editorial da edição aqui analisada encontremos o seguinte texto, assinado pelo redator-chefe Tato Coutinho: "Não vou dizer no meu tempo, que parece coisa de gente muito velha, mas houve um tempo em que ouvir música era na vitrola e você precisava de um disco. Disco não, um LP - não era nem CD..."19.

No mesmo número, na única matéria a abordar explicitamente a diferença, retratando o cotidiano de uma garota portadora de deficiência física, o que se ressalta é a superação de limites, uma vez que Edênia Garcia, de 18 anos, tornou-se uma atleta de sucesso, com "medalha de prata em natação nas Paraolimpíadas de Atenas" ${ }^{20}$. Como ela mesma diz, "Aprendi que não somos diferentes de ninguém. Precisamos de algumas coisas especiais, mas não somos diferentes" 21 . Curioso notar, ao lado da reportagem com Edênia, a publicidade da revista Boa Forma, com a seguinte chamada: "Deixe de comer carboidratos à noite e fique em forma todos os dias"22.

A mitificação do ser jovem, a articulação entre o consumo e a construção identitária, ambos solapam a pretensão à diferença. $\mathrm{Na}$ verdade, como discurso subjacente articulando a revista analisada, vimos ressoar a afirmação de uma diferença que torna igual, de uma variação que reafirma e confirma o mesmo. Seja jovem, bela, dócil, atualizada. Misture estilos, como preconiza a indústria da moda.

Seja diferente, seja capaz de mixar estilos, exatamente como o fazem as famosas. Aquelas mesmas que só estão na moda por serem perfeitamente diferentes. E perfeitamente iguais nesta diferença. Seja diferente. Para ser você mesma. Igual àquelas tantas outras que, como você, são diferentes. E, não se esqueça, tenha paciência. Todos os dias. E faça, de sua identidade, este eterno remix. E não fale no meu tempo.

19. Ibid., p. 6.

20. Ibid., p. 95-96.

21. Ibid., p. 96. 22. Ibid., p. 94. 
O passado só vale se for forjado, como no caso da onda das camisetas surradas. Lembremos-nos, afinal, de que essa camiseta novinha em folha "que já vem com as marcas do desgaste do tempo dá a sensação de que não existe outro igual". E, de fato, o tempo transformado em valor de marca não será vivido. Ele pode ser vestido: "faz de conta, vai!"

Resumo: A crítica proposta apresenta de modo sintético possíveis operadores conceituais para a análise da mídia jovem, focando especificamente sua inserção em processos sociais e culturais de visualidade e visibilidade. Discute, em um estudo de caso específico, como a dinâmica midiática, de um ponto de vista formal e no modo como agencia seus conteúdos, interage e interfere na produção imaginária do jovem e do juvenil.

Palavras-chave: juventude, mídia, imagem, identidade, diversidade.
Abstract: This critical presents in a synthetic view some conceptual operators utilized to analyses "youth media", focusing specifically this insertion in social and cultural processes of visuality and visibility. Discusses, in a specific case, how the mediatic dynamic, in a formal point of view and in the organization of their contents, interact and interfere in the imaginary production of the young people and of youth.

Keywords: youth, media, image, identity, diversity. 